DOI: 10.17805/trudy.2018.6.4

\title{
ВЛИЯНИЕ ПЕРВОЙ МИРОВОЙ ВОЙНЫ НА ПРОБЛЕМАТИКУ ОТЕЧЕСТВЕННОЙ ПЕДАГОГИЧЕСКОЙ ПСИХОЛОГИИ (ПО МАТЕРИАЛАМ ДЕЯТЕЛЬНОСТИ САНКТ-ПЕТЕРБУРГСКОГО РОДИТЕЛЬСКОГО КРУЖКА)
}

\author{
И. В. Усольцева \\ ФГБНУ «Институт изучения детства, семьи и воспитания \\ Российской академии образования»
}

\begin{abstract}
Аннотация: В статье анализируется влияние Первой мировой войны на проблематику отечественной педагогической психологии по материалам авторитетной в то время организации - Санкт-Петербургского Родительского кружка. Делается вывод о том, что это влияние сказалось в постановке проблемы взаимосвязи ребенка и общества, осмысления уникальности взросления в военное время, а также уменьшения травматического влияния войны на детей.

По материалам научного доклада на конференции «Кросс-культурные и междисциплинарные исследования в истории психологии: результаты и перспективы» (Москва, 24-25 ноября 2018 г.), проведенной в рамках проекта № 18-513-18017, поддержанного РФФИ.

Ключевые слова: Первая мировая война; история психологии; история отечественной педагогической психологии; Санкт-Петербургский родительский кружок

\section{THE INFLUENCE OF THE FIRST WORLD WAR ON THE ISSUES OF RUSSIAN EDUCATIONAL PSYCHOLOGY (ON MATERIALS OF THE SAINT PETERSBURG PARENTS' CIRCLE)}

\section{V. Usoltseva}

The Federal State Budget Scientific Institution "Institute of Study of Childhood, Family and Education of the Russian Academy of Education"

Abstract: The article analyzes the influence of the First World War on the issues of the domestic educational psychology based on the materials of a then authoritative organization Saint Petersburg Parents' Circle. The author concludes that this influence reflected itself in the following issues: the relationship between the child and society, understanding the uniqueness of adolescence during wartime, as well as reducing the traumatic impact of the war on children.

The research is based on the materials of the scientific reportat the conference "Cross-Cultural and Interdisciplinary Studies into the History of Psychology: Results and Prospects" (Moscow, 24-25 November 2018), held within the project No. 18-513-18017 supported by RFBR.

Keyworlds: First World War; history of psychology; history of the domestic educational psychology, Saint Petersburg Parents' Circle

На основе журнальных публикаций членов Санкт-Петербургского Родительского кружка (1884-1918) и протоколов его заседаний в 
1914-1918 гг. в статье дается оценка влияния Первой мировой войны на проблематику отечественной педагогической психологии.

Это оказывается возможным, поскольку эта научно-педагогическая организация занимала важнейшее место в организационном пространстве отечественной науки в дореволюционное время. Санкт-Петербургский Родительский кружок (СПбРК) (1884-1918) существовал как государственное (при Педагогическом музее Главного управления военно-учебных заведений) и общественное (с 1906 г.) научное общество, хотя в силу бюрократических причин того времени не мог им именоваться, так как не был организован при университете (Арепьев, 1906; Каптерев, 1884; Педагогический музей ..., 1914).

Членами кружка были многие известные деятели образования, медицины, психологи, философы, кадровые военные, священники, издатели (А. И. Введенский, А. С. Вирениус, В. В. Волкович, Я. Г. Гуревич, А. М. Калмыкова, П. Ф. Каптерев, П. И. Ковалевский, П. Ф. Лесгафт, А. Н. Макаров, А. Н. Острогорский, 3. К. Столица, Э. П. Шаффе и др.), а результаты его деятельности («Энциклопедия семейного обучения и воспитания» (1898-1910), журнал «Воспитание и обучение» (1877-1917)) достаточно хорошо известны и в современной науке.

Члены кружка выступили организаторами первой Всероссийской выставки детских игрушек, игр и занятий (1890 г., Санкт-Петербург), первого Всероссийского съезда по семейному воспитанию (1912-1913 гг., Петроград). Они приняли активное участие в деятельности почти всех всероссийских съездов по проблемам образования, а также курсов, выставок, комиссий конца XIX - начала XX века. Ими были организованы первые консультации для родителей по вопросам ухода, воспитания, обучения и развития детей (кабинеты). В 1913 г. функционировало три таких кабинета (Педагогическая хроника, 1914а). Также существовала бесплатная воскресная школа.

Члены Родительского кружка «выросли» до крупных деятелей медицины и педагогики советского периода, сохранив в своей деятельности преемственность между дореволюционным и «советским» периодами в развитии психолого-педагогического знания. Среди них Наталья Алексеевна Альмединген-Тумим (1883-1843), профессор (с 1919 г.), а затем ректор Петроградского педагогического института дошкольного образования (будущий Ленинградский государственный педагогический институт им. А. И. Герцена) (1923-1924), там же заведовала кафедрой дошкольной педагогики (1925-1929); Елизавета Ивановна Тихеева (1867-1943), профессор этого института, руководитель опытного детского сада при нем; Лидия Ивановна Тихеева-Чулицкая (1868-1938), заведующая отделением и кафедрой педологии раннего детского возраста Ленинградского научно-практического Института охраны материнства и младенчества (с 1935 г. - педиатрического медицинского института), профессор кафедры соматической педологии Института физического образования имени П. Ф. Лесгафта. 
Научные труды Московского гуманитарного университета 2019 № 1

Изучение деятельности СПбРК дает ценный материал для исторических исследований отечественной науки. На материалах докладов участников и протоколах заседаний Родительского кружка изучены особенности понимания семейного воспитания в XIX века (Кудряшёв, 2015; Усольцева, 2018), рассмотрены проблемы взаимодействия родителей, врачей и педагогов (Байфорд, 2013: Электр. ресурс), проанализировано формирование междисциплинарной научной картины мира отдельной научной дисциплины (Усольцева, 2017) и т. д.

В процессе становления и развития отдельных научных дисциплин требуется немало времени для формирования устойчивого целостного ядра знаний, принципов, норм, убеждений, которые формируют логико-гносеологические и философско-методологические основания, предметное содержание и проблемное поле научной дисциплины (Усольцева, 2017).

Такая динамика происходила на протяжении почти 30 лет деятельности СПбРК. Его участниками специальная задача формирования дисциплинарного статуса педагогической психологии не ставилась. Однако она была объективно решена, как это часто бывает в науке, как побочный продукт интеллектуальной коллективной, консубстанциональной (Н. О. Лосский) работы членов кружка.

Деятельность СПбРК осуществлялась в ходе принципиальных научных дискуссий по ключевым вопросам, она была целенаправленным (ставились задачи изучения тех или иных явлений), структурированным (создавались комиссии и подкомиссии по разным вопросам) научным поиском. В кружке велись протоколы, ключевые доклады его членов регулярно публиковались в научной печати. Деятельность кружка имела резонанс в российском (Арепьев, 1906; Педагогический музей ... , 1914) и, согласно данным П. А. Лебедева (Лебедев, 1998: 13), - и в международном педагогическом сообществах. Деятельность кружка была по достоинству оценена современным ему обществом. Городское управление в 1914 г. назначило кружку ежегодное пособие в размере 600 рублей (Педагогическая хроника, 1914c: 189).

Эти факты говорят о значимости кружка в дореволюционной России, что позволяет утверждать: его деятельность на протяжении более 30 лет оказывала огромное влияние на логико-гносеологические, ценностно-смысловые и методологические компоненты индивидуальных научных картин мира профессиональных педагогов и педагогических психологов (педологов), руководителей государственных и частных образовательных учреждений, а также врачей, издателей учебной и детской литературы и литературы для родителей, производителей наглядных пособий и производителей игрушек и других специалистов, работавших с детьми в России.

Поэтому мы считаем, что анализ влияния Первой мировой войны на развитие проблематики отечественной педагогической психологии, построенный на материалах СПбРК, имеет под собой веские основания.

С 1906 г. СПбРК вышел из состава Педагогического музея и продолжил 
свою работу как общественное научное общество до 1918 года (Арепьев, 1906). Именно на этот период его деятельности и пришлась Первая мировая война (1914-1918).

Как и у любого крупного события, у Первой мировой войны существовал период до ее начала де-юре, когда война еще не была объявлена, но она уже «висела в воздухе», существовала де-факто. Общественные настроения фиксировали неудовлетворенность положением России в мировом политическом пространстве, отсутствие уважения и самоуважения к достижениям русской культуры и науки и т. д.

Эти умонастроения нашли отражение в деятельности ключевых фигур СПбРК на втором этапе его деятельности. Среди них наиболее известны П. И. Ковалевский, председатель кружка, В. А. Волкович и 3. К. Столица, секретари кружка.

Поскольку эти персоналии не воспринимаются пока психологической общественностью как часть научного наследия отечественной психологии, позволим себе привести их краткие биографические сведения. Павел Иванович Ковалевский (1850-1931) - психиатр, публицист и общественный деятель, профессор и декан медицинского факультета Императорского Харьковского университета, профессор и ректор Императорского Варшавского университета, профессор Императорского Казанского университета и Императорского Санкт-Петербургского университета. Он известен своими трудами по психолого-психиатрическому анализу исторических личностей и участию в крайне правых политических организациях (Русский национальный клуб, Совет Всероссийского национального союза, Русское собрание) (Струкалов, 2015).

Вера Акинфеевна Волкович (1873-1962) получила образование на Высших женских курсах, где была оставлена при кафедре психологии, также преподавала в Женском Педагогическом институте. В. А. Волкович была членом Санкт-Петербургского философского общества, написала большое число работ по философии, по психологии и педагогике, после революции защитила кандидатскую диссертацию. Она участница международных конгрессов по народному образованию и общественному воспитанию. Во время Первой мировой войны была сестрой милосердия (Ванчугов, 1996).

Зинаида Константиновна Столица (1879-1956), также закончившая Высшие женские курсы, была соратницей В. А. Волкович во многих начинаниях. Они совместно вели отдел критики и библиографии в журнале «Вопросы философии и психологии», а также открыли «Философские курсы», которые были направлены на развитие у слушателей философского и педагогического мировоззрения. З. К. Столица была членом Санкт-Петербургского Философского общества, преподавала в Женском педагогическом институте, в качестве психолога принимала участие в Съезде по психоневрологии в Москве (1923), где выступила с докладом «Метод целостного подхода к изучению личности ребенка дошкольного возраста» (Ванчугов, 1996). 
Научные труды Московского гуманитарного университета 2019 № 1

В предвоенные годы руководители кружка опубликовали свои работы, важные для формирования проблематики отечественной педагогической психологии. П. И. Ковалевский написал «Национализм и национальное воспитание в России» в 2 ч. (СПб., 1912), «Основы русской нации» (СПб, 1912), В. А. Волкович - «Будущее в наших руках» (СПб., 1910, в соавторстве с 3. К. Столицей), «Друг человечества Н. И. Пирогов (К 100-летию со дня рождения. 1810-1910)» (СПб., 1910), среди работ 3. К. Столицы того периода наиболее известны «Развитие в детях жизнерадостности и борьба с пессимизмом» (СПб., 1912), «Выработка характера» (СПб.-М., 1912).

Даже только читая названия указанных произведений, мы видим акцентирование проблем национального (само)сознания в работе кружка в довоенные годы.

На предыдущем этапе существования СПбРК, когда он был официальным отделом Педагогического музея, конечно, происходило сравнение российского образования с зарубежным (этому посвящены несколько томов «Энциклопедии...», отражено на заседаниях кружка и в публикациях его членов), но именно в предвоенную эпоху и в самом начале войны, как нам представляется, начинает отчетливо звучать тема гордости за русское и российское.

«Национализм, - писал П. И. Ковалевский, - это проявление уважения, любви и преданности до самопожертвования в настоящем, почтения и преклонения перед прошлым и желания благоденствия, славы, мощи и успеха в будущем той нации, тому народу, к которому данный человек принадлежит» (Ковалевский, 1922: 10).

Это движение к национальному (само)осознанию и принятию нашло свое отражение во взглядах многих ученых и философов того времени (Белогурова, 2006). Вероятно поэтому, в самом своем начале Первая мировая война воспринималась по аналогии с Отечественной войной 1812 г., рождая всплеск патриотизма и готовности к самопожертвованию.

Инициированное ростом интереса к национальному самосознанию происходит расширение предмета педагогической психологии: от семьи к школе (на первом этапе) и от школы - к обществу (на втором этапе). Анализируя влияние школы на становление гражданственности и патриотизма, П. И. Ковалевский делает неутешительный вывод: «школа убила Бога, убила национальность, убила государственность, убила общество, убила семью, убила человека» (Ковалевский, 1922: 237). Взгляды В. А. Волкович и 3. К. Столицы на роль школы в формировании детской личности менее радикальны, но столь же неутешительны.

Реформирование школы обществом, которое будет звучать с 1906 г. на заседаниях кружка, в публикациях его членов, в их выступлениях на всероссийских съездах, - только одна из конкретизаций проблемы национального (само)сознания.

На первом Всероссийском съезде по семейному воспитанию (1912-1913), который был организован членами СПбРК (К предстоящему 
Съезду ... , 1912), будет дискутироваться вопрос о соотношении семейного и общественного (детсадовского) воспитания как один из центральных вопросов съезда. Только общественное воспитание, считали многие педагоги, разделявшие позицию кружка, поможет ребенку осознать свою принадлежность к своей нации, воспитает любовь к природе, истории и культуре своей страны (Труды ..., 1914).

С началом войны члены кружка активно включаются в практическую работу, которую можно было бы назвать «охрана детства».

Нормальное взросление детей и особенно подростков под влиянием тягостных впечатлений военного времени (раненные с фронта, большое число убитых, депрессивные настроения взрослых, уход кормильцев из дома, трудности с продовольствием и другие) оказалось под угрозой.

Члены СПБРК вошли в состав Комиссии попечения о детях при «Комитете помощи пострадавшим от войны», организованном газетой «Школа и жизнь», который так охарактеризовал одну из целей своей деятельности: «участие педагогически образованных людей во всех тех ячейках, которые уже устроены для детей в виде яслей, садов, приютов и пр. Ибо еще не было в жизни России того момента, когда так необходима была бы активная пропаганда правильно поставленного общественного воспитания. Переживаемое нами время таит в себе неиссякаемые силы - добрые и недобрые - для образования человеческой личности; подрастающее поколение формируется теперь при небывалых условиях, требующих от его руководителей вдумчивой и неустанной работы» (Педагогическая хроника, 1914b: 315-316).

Осознание и принятие своей культурно охранительной миссии было характерно, как показало исследование Е. Ю. Семеновой (Семенова, 2013), для многих просветительских обществ того времени. Они буквально открыли свои двери для широких слоев населения под воздействием потребности «социума в духовном общении, восприятии культурных ценностей, которые компенсировали эмоциональное перенапряжение, вызванное мыслями о войне» (там же: 42).

Тема «дети и война» постепенно вытесняет другую проблематику из работы СПбРК. Она осмысливается с теоретических позиций (зафиксировать особенности восприятия войны детьми, проследить влияние войны на их личность и т. д.), но и также с методических. С. Золотарева, Е. Иорданская, А.М. Калмыкова и другие выступают с докладами, публикуют свои и перепечатывают чужие, близкие им по духу, статьи в журнале «Воспитание и обучение», чтобы ответить на важный вопрос: как взрослые могут помочь детям пережить войну. «Война тянется, но дети должна расти, им нужно иметь постоянный приток нормальной духовной пищи» (Золотарева, 1915: 21).

Если в первый период войны угроза взрослению детей осознавалась педагогическим сообществом как духовная, то с течением времени эта угроза приобрела уже характер физической угрозы существованию детей в виде смерти на фронте (для сбежавших туда подростков), голода в тылу, отсутствия жилья, средств для существования и т. д. 
Научные труды Московского гуманитарного университета 2019 № 1

В этот период члены кружка проявили себя не только хорошими учеными, но и хорошими людьми. Они читали платные лекции, средства от которых шли на содержание детских приютов (общежития, очаги, колонии в терминологии того времени), бесплатно проводили в них занятия с детьми, искали детям места работы или учебы, выезжали с детьми на природу в летние месяцы, собирали для них одежду, книги, игрушки.

Совершенно отдельным направлением была работа по организации общественно-полезного досуга подростков, чтобы предотвратить их побеги на фронт. «Совет кружка обратился с воззванием «Дети, помогите!» чтобы дети помогли, чем смогут своим сверстникам. На этот призыв отозвались многие» (Педагогическая хроника, 1914d: 382). Кроме того, Совет кружка взял на себя «обязанность добывать всем чинам действующей армии по их запросам частные и официальные сведения о положении их детей» (там же).

И даже в этот практико-ориентированный период социального подвижничества в деятельности СПбРК, в это тяжелое военное время, члены кружка продолжают свою «научную работу». Матери пишут дневники, следя за развитием своих детей в военное время, проводится анализ детских рисунков на тему войны, ставится вопрос о возможности полноценного воспитания ребенка одной лишь матерью и т.д. Военное время начала $\mathrm{XX}$ века в полной мере показало обусловленность возникновения научных проблем социокультурной детерминаций, на что указывает в своих работах Ю. Н. Олейник (Олейник, 2018).

Таким образом, Первая мировая война (1914-1918) оказала существенное влияние на проблематику отечественной педагогической психологии. Были поставлены, хотя и не полностью решены вопросы, выходящие за ее дисциплинарные «границы»: национальное самосознание и его воспитание в школе и обществе, проблемы нравственности, политической активности, участия родителей в управлении школьным образованием и др.

Для нас особенно важно, что в этот период отечественная педагогическая психология максимально близко подошла к изучению ребенка как части общества («природа - семья - ребенок - общество»), выйдя за рамки анализа «ребенок - его психология и физиология», «ребенок - школа и педагогический процесс».

Под влиянием событий Первой мировой войны, предшествующего ему этапа деятельности СПбРК наметилась тенденция к анализу всей совокупности детерминант развития ребенка: биологических, психологических, педагогических, социальных. А такое оформление предметного содержания, проблемного поля и логико-гносеологических средств его познания в отечественной педагогической психологии могло успешно разрабатываться только на основе междисциплинарного синтеза. В этой направленности на междисциплинарную полифонию научного представления о ребенке мы видим преемственность в деятельности СПбРК и считаем ее системообразующим основанием отечественной педагогической психологии. 


\section{СПИСОК ЛИТЕРАТУРЫ}

Арепьев, Н. Ф. (1906) Родительский кружок в Петербурге. СПб. : Т-во худож. печати. 39 с.

Байфорд, Э. (2013) Родитель, учитель и врач: к истории их взаимоотношений в деле воспитания и образования в дореволюционной России [Электронный ресурс] // Новые российские гуманитарные исследования. № 8. URL: http://nrgumis.ru/articles/archive/2013-8/pedagogika/ (дата обращения: 18.01.2016).

Белогурова, Т. А. (2006) Отражение общественных настроений в российской периодической печати 1914 - февраля 1917 гг.: автореф. дис. ... канд. ист. н. Брянск. 24 с.

Ванчугов, В. В. (1996) Женщины в философии. Из истории философии в России конца. М. : РИЦ ПИЛИГРИМ. 304 с.

Золотарева, С. (1915) Война и вопросы воспитания // Воспитание и обучение. № 1. С. 1-24.

К предстоящему Съезду по семейному воспитанию (1912) // Воспитание и обучение. № 12. С. 387-390.

Каптерев, П. Ф. (1884) Родительский кружок в Соляном городке при школьно-гигиеническом отделе педагогического музея // Воспитание и обучение. № 1. С. 1-7.

Ковалевский, П. И. (1922) Психология русской нации: в 2 т. Перепечатка с 3-го доп. издания 1912 г. Нью-Йорк : Изд-во «Союз единения России». 333 с.

Кудряшёв, А. В. (2015) Общественные дискуссии конца XIX - начала XX века о взаимодействии семьи и школы // Проблемы современного образования. № 2. С. 76-85.

Лебедев, П. А. (1998) Психолого-педагогическое наследие П. Ф. Каптерева. М. : б. и. 144 с.

Олейник, Ю. Н. (2018) История психологии как история научных проблем: проблемологический подход // Институт психологии Российской академии наук. Человек и мир. Т. 2. № 1. С. 20-40.

Педагогическая хроника (1914а) // Воспитание и обучение. № 1. С. 27-28.

Педагогическая хроника (1914b) // Воспитание и обучение. № 10. С. 314-315.

Педагогическая хроника (1914c) // Воспитание и обучение. № 5. С. $188-189$.

Педагогическая хроника (1914d) // Воспитание и обучение. № 12. С. 377-382.

Педагогический музей военно-учебных заведений. 1864-1914. Исторический очерк (1914) / под ред. Я. Л. Барскова. СПб. : б. и.

Семенова, Е. Ю. (2013) Влияние Первой мировой войны на мировоззрение, общественные настроения и поведенческие практики городского населения поволжских губерний Российской империи (июль 1914 г. - февраль 1917 г.) : автореф. дисс. ... Д-ра ист. наук. Саратов. 50 с. 
Стукалов, П. Б. (2015) П. И. Ковалевский - ученый, публицист, идеолог консервативного национализма // Вопросы истории консерватизма. № 1 . С. 345-355.

Труды первого всероссийского съезда по семейному воспитанию (1914): в 2 т. Петроград.

Усольцева, И. В. (2017) Вклад Санкт-Петербургского Родительского кружка в становление междисциплинарной научной картины мира отечественной педагогической психологии // Мир психологии. № 2 (90). С. 53-66.

Усольцева, И. В. (2018) Проблема взаимодействия семьи и школы в отечественной педагогической психологии в конце XIX - начале XX века // Журнал педагогических исследований. Т. 3. № 1. С. 48-66.

Дата поступления: 15.01.2018 2.

Усольцева Инесса Владимировна - кандидат психологических наук, доцент, ведущий научный сотрудник лаборатории развития воспитания и социализации детей ФГБНУ «Институт изучения детства, семьи и воспитания Российской академии образования». Адрес: 121096, Россия, г. Москва, 3-я Филевская, д. 6. Тел.: +7 (915) 277-11-73. Эл. адрес: iv-usoltseva@yandex.ru

Usoltseva Inessa Vladimirovna, Candidate of Psychology, Associate Professor, Leading Research Fellow, Laboratory of Child Development and Socialization, Federal State Budget Scientific Institution "Institute of Study of Childhood, Family and Education of the Russian Academy of Education". Postal address: 6, 3rd Filyovskaya St., Moscow, Russian Federation, 121096. Tel.: +7 (915) 277-11-73. E-mail: iv-usoltseva@yandex.ru

\section{Для цитирования:}

Усольцева И. В. Влияние Первой мировой войны на проблематику отечественной педагогической психологии (по материалам деятельности Санкт-Петербургского родительского кружка) [Электронный ресурс] // Научные труды Московского гуманитарного университета. 2019. № 1. URL: http://journals.mosgu.ru/trudy/article/view/931 (дата обращения: дд.мм.гг.). DOI: 10.17805/trudy.2019.1.4 